\title{
Study on the Structure of Peroxide Cross-Linked Polyethylene Pipes with Several Stabilizers
}

\author{
Hideo Hirabayashi ${ }^{1}$, Akinori Iguchi ${ }^{1},{\text { Kazushi } \text { Yamada }^{2 *}, \text { Hiroyuki Nishimura }^{2} \text {, Kazuhisa Ikawa }}^{3}$, \\ Hidekazu Honma ${ }^{4}$ \\ ${ }^{1}$ Shinwa Sangyo Co., Ltd., Osaka, Japan; ${ }^{2}$ Kyoto Institute of Technology, Kyoto, Japan; ${ }^{3}$ Osaka Gas Co., Ltd., Osaka, Japan; ${ }^{4}$ KRI. \\ Inc., Osaka, Japan. \\ Email: *kazushi@kit.ac.jp
}

Received June $26^{\text {th }}$, 2013; revised July 25 ${ }^{\text {th }}, 2013$; accepted August $5^{\text {th }}, 2013$

Copyright (C) 2013 Hideo Hirabayashi et al. This is an open access article distributed under the Creative Commons Attribution License, which permits unrestricted use, distribution, and reproduction in any medium, provided the original work is properly cited.

\begin{abstract}
Cross-linked polyethylene (PEX) pipes used in hot water supply are required for high mechanical strength and high creep resistance at high temperature. Especially PEX-a pipes which are made by peroxide cross-linking have better performance, such as creep resistance and thermal shock resistance than the pipes made by the other cross-linking method. Because the PEX-a pipes indicate the higher cross-link degree as compared with the other PEX pipes. In this study, the PEX-a pipes which were mixed with several stabilizers were tested to evaluate the effects on cross-link degree and the oxygen induction time. And also they are evaluated with the chlorine aqueous solution by the performance of the long-term hydrostatic pressure test and the long-term hydro dynamic pressure test. As a result, it was found that the combination of antioxidants for PEX-a pipes plays an important role to prolong the oxygen induction time without inhibiting the cross-linking. From the results of the ${ }^{1} \mathrm{H}$ pulsed NMR measurement over the melting point of polyethylene, it was found that each peroxide PEX pipe with different antioxidant combinations indicated the different proportion and crosslink density of cross-linked region, in addition, that these pipes had the effective structure of cross-linking for the hydrostatic and hydrodynamic pressure test with the chlorine aqueous solution. Therefore, it was considered to be useful results for studies of the stricture of cross-linking of polyethylene.
\end{abstract}

Keywords: Cross-Linked; Polyethylene; PEX-a; Peroxide; Structure of Cross-Linking

\section{Introduction}

Recently, the polyethylene pipes with the performance of high strength and creep resistance are used commonly in domestic houses instead of metal pipes. Many researchers had investigated the mechanical properties [1-5], durability [6-9], or lifetime prediction [10,11] of the plastic pipes such as polyethylene pipes, cross-linked polyethylene pipes, complex pipes, etc. It has been well known for a long time that polyethylene pipes under pressure exhibit a ductile failure at short-term and a brittle failure at long-term. However, the major drawback of polyethylene as compared with other polymers is its relatively low upper use temperature. By cross-linking, this limitation is overcome and the upper use temperature is increased. Controlled cross-linking provides a polymer with outstanding physical and heat resistant properties without impairing other essential characteristics. On the

\footnotetext{
"Corresponding author.
}

other hand, three types of cross-linking method were wellknown for producing cross-linked polyethylene pipes. PEX-a pipes are produced using the Peroxide (or, "Engel") method, named after the inventor Tomas Engel. PEX-b pipes are produced using the "Silane" or "Moisture Cure" method of cross-linking. PEX-c pipes are manufactured using the "Electronic Irradiation" method of cross-linking. For PEX-a, during the manufacturing process, free radicals were generated when polyethylene polymer was melted and cross-links between molecules occurred at the high temperature and the high pressure that exceed the decomposition temperature of the polymer [12]. And PEX-a pipes offered the greatest resistance to creep at high temperature, crack propagation, and high impact over PEX-b and PEX-c pipes. The peroxide method was regarded as having an advantage in easy compounding and rapid cross-linking. However as the time of cross-linking was too short, it was considered to be difficult to control the uniformity and the structure 
of cross-linking [13]. There are few researches for the relationship between PEX pipes, mechanical properties and additives. Therefore, it is very important to investigate the effect of additives for the mechanical properties of PEX pipes.

In this study, the PEX-a pipes which were mixed with several stabilizers were tested to examine the effects on degree of cross-linking and the oxygen induction time. And also they are tested to evaluate the performance of the hydrostatic pressure test and the hydrodynamic pressure test with the chlorine aqueous solution and examined the structure of cross-linked region with the ${ }^{1} \mathrm{H}$ pulsed NMR.

\section{Experimental}

\subsection{Outline of Peroxide Cross-Linked Polyethylene Pipes}

The peroxide cross-linking was to be reacted polyethylene mixed with peroxide under high temperature and high pressure. During the manufacturing process, free radicals were generated when polyethylene polymer was melted and cross-links between molecules occurred at the temperature that exceeded the decomposition temperature of the polymer. When the free radicals were generated, it had negative effects on block of cross-linking by some of stabilizers.

$$
\begin{aligned}
& \mathrm{R}^{\prime \prime}-\mathrm{O}-\mathrm{O}-\mathrm{R}{ }^{\prime \prime} \stackrel{\Delta}{\longrightarrow} 2\left(\mathrm{R}^{\prime \prime}-\mathrm{O}\right) \\
& \mathrm{R} "-\dot{\mathrm{O}}+\mathrm{RH} \longrightarrow \mathrm{H} \longrightarrow \mathrm{R} \text { " }-\mathrm{OH}+\mathrm{R} \\
& \mathrm{R}+\mathrm{R} \longrightarrow \mathrm{R}-\mathrm{R} \\
& (* \mathrm{R}-\mathrm{H} \text { : polyethylene molecules })
\end{aligned}
$$

\subsection{Manufacturing Process of Peroxide Cross-Linking Specifications}

Figure 1 shows the Ram extruder for peroxide crosslinking polyethylene pipes. Table 1 shows the manufacturing condition of the Ram extraction [12].

\subsection{Test Materials}

\subsubsection{Testing Pipes}

The testing materials mixed with several stabilizers were made to the testing pipes by using the Ram extruder as shown in Figure 1. The nominal size of the testing pipes was 13A specified by JIS K6769.

\subsubsection{Raw Materials}

Table 2 shows the physical properties of polyethylene resin for peroxide cross-linking polyethylene pipes.

\subsubsection{Cross-Linking Agent}

Table 3 shows the specification of cross-linking agent

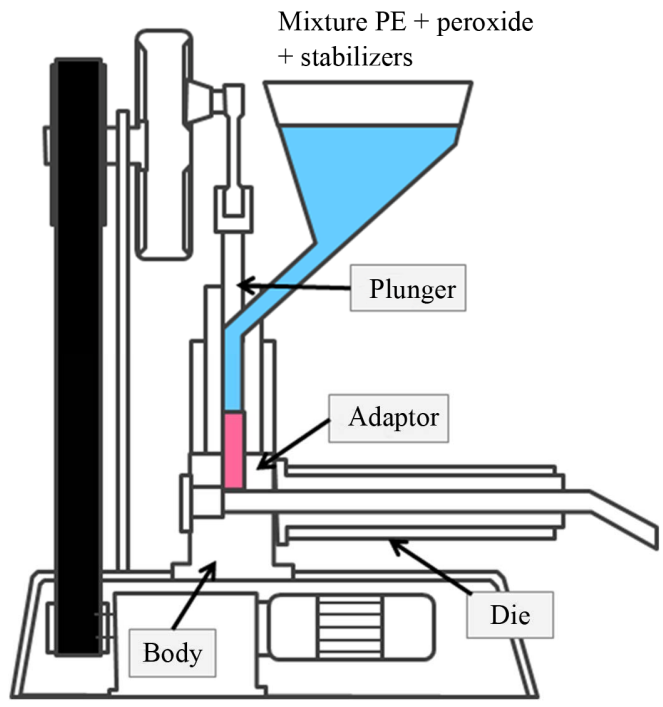

Figure 1. Schematic drawing of Ram extruder.

Table 1. Manufacturing condition of Ram extraction.

\begin{tabular}{ccc}
\hline & Unit & Value \\
\hline Body temperature & ${ }^{\circ} \mathrm{C}$ & $110 \pm 5$ \\
Adopter temperature & ${ }^{\circ} \mathrm{C}$ & $170 \pm 5$ \\
Die temperature & ${ }^{\circ} \mathrm{C}$ & $250 \pm 5$ \\
Extrusion speed & $\mathrm{m} / \mathrm{min}$ & $2.1 \pm 0.2$ \\
\hline
\end{tabular}

Table 2. Physical properties of polyethylene resin for peroxide cross-linking polyethylene pipes.

\begin{tabular}{ccc}
\hline & Unit & Value \\
\hline Density & $\mathrm{g} / \mathrm{cm}^{3}$ & 0.9477 \\
$\begin{array}{c}\text { Number average molecular } \\
\text { weight (Mn) }\end{array}$ & - & $5.48 \times 10^{4}$ \\
$\begin{array}{c}\text { Weight average molecular } \\
\text { weight (Mw) }\end{array}$ & - & $2.27 \times 10^{5}$ \\
$\begin{array}{c}\text { Molecular weight distribution } \\
\text { (Mw/Mn) } \\
\text { Melt flow rate (MFR) } \\
\text { Melting point (Tm) }\end{array}$ & - & 4.14 \\
Type of co-monomer & ${ }^{\circ} \mathrm{C}$ & 0.22 \\
Number of branch & - & Bumbers/1000C \\
\hline
\end{tabular}

Table 3. Specification of cross-linking agent.

\begin{tabular}{ccc}
\hline & Unit & Value \\
\hline Degree of purity & $\%$ & $>95$ \\
Content of hydro peroxide & $\%$ & $<0.5$ \\
\hline
\end{tabular}

for peroxide cross-linking polyethylene pipes. 


\subsubsection{Stabilizers}

Table 4 shows the physical properties of stabilizers for peroxide cross-linking polyethylene pipes.

\subsection{Test Method}

\subsubsection{Measurement of Oxidation Induction Time}

The oxidative induction time (OIT) was measured from samples taken from pipes mixed with several stabilizers at $210^{\circ} \mathrm{C}$ under oxygen atmosphere by using the differential scanning calorimeter, Shimadzu, DSC-50A.

\subsubsection{Measurement of Crosslink Degree}

The crosslink degree was also measured from samples taken from pipes mixed with several stabilizers. The conditions for the crosslink degree measurement were followed by JIS K6769:2004 "Cross-linked polyethylene (PE-X) pipes". The crosslink degree was calculated from gelation after the Soxhlet extraction.

\subsection{Evaluating Method for Lifetime Prediction}

\subsubsection{Hydrostatic Pressure Test}

The testing pipes integrated with several stabilizers were evaluated by the hydrostatic pressure test. The conditions of the hydrostatic pressure test were followed to ISO 1167: 2006, "Thermoplastics pipes, fittings and assemblies for the conveyance of fluids - Determination of the resistance to internal pressure -". The test was carried out with water-filled pipes in air as the outer environment at $110^{\circ} \mathrm{C}$ and $115^{\circ} \mathrm{C}$. The $0.4 \mathrm{~m}$ long pipes were fitted with commercialized bronze fittings.

\subsubsection{Hydrodynamic Pressure Test with the Aqueous Solution}

The testing pipes integrated with several stabilizers were evaluated by the hydrodynamic pressure test with the aqueous chlorine solution. The conditions of the hydrodynamic pressure test were followed to ASTM F2023 "Evaluating the oxidative resistance of cross-linked polyethylene (PEX) tubing and systems to hot chlorinated water". The test was carried out with a chlorine concentration of 3 ppm, pH 6.8 and the flow rate of 54 $\mathrm{dm}^{3} / \mathrm{h}$. The $0.4 \mathrm{~m}$ long pipes were fitted with commercialized bronze fittings.

\subsubsection{Molecular Weight between Cross-linking Points} Samples taken from pipes mixed with several stabilizers were examined with Rheometric Solids Analyzer, Rheometric Scientific, RSA III [14].

\subsubsection{Structure of Cross-Linking Region Measurement}

Samples taken from pipes mixed with several stabilizers were examined with the ${ }^{1} \mathrm{H}$ pulsed NMR, JEOL, NMR-
MU25 [15].

\section{Results and Discussion}

\subsection{Measurement of Oxidative Induction Time and Crosslink Degree}

Figure 2 shows the measurement of the oxidative induction time and crosslink degree of the pipes which were mixed with $2000 \mathrm{ppm}$ of PH1, 2000 ppm of PH2, 1000 ppm of HA1, 2000 ppm of PH5 and also mixed with varying concentration from $0 \mathrm{ppm}$ to $3000 \mathrm{ppm}$ of HA2 of hindered amine light stabilizers.

It was found that the oxidative induction time was able to persist for a long time in case of the mixing with 2 types of hindered phenol stabilizers, 1 type of metal deactivator, 1 type of high molecular hindered amine light stabilizer and mixed with varying 1 type of high-molecular hindered amine light stabilizer. And also this mixture of stabilizers had no effect on the crosslink degree and held the high crosslink degree.

Figure 3 shows the measurement of the oxidative induction time and crosslink degree of the pipes which were mixed with 2000 ppm of PH1, 2000 ppm of PH2, 1000 ppm of HA1, 2000 ppm of PH5 and mixed with varying concentration from $0 \mathrm{ppm}$ to $5000 \mathrm{ppm}$ for HA3 of hindered amine light stabilizers.

It was also found that the oxidative induction time was able to persist for a long time in case of mixing with 2 types of hindered phenol stabilizers, 1 type of metal deactivator, 1 type of high molecular hindered amine light stabilizer and mixed with varying 1 type of low-molecular hindered amine light stabilizer. And also this mixture of stabilizers had no effect on the crosslink degree and held the high crosslink degree.

From these results, the pipes mixed with 2 types of stabilizer combinations were evaluated by hydrostatic pressure test and hydrodynamic pressure test with the chlorine aqueous solution, as compared with combination No.1 sample. One stabilizer combination was No.2 in Table 5 as the pipes which were mixed with 2000 ppm of PH1, 2000 ppm of PH2, 1000 ppm of high-molecular HA1, 2000 ppm of high-molecular PH5 and 3000 ppm of HA2. Another stabilizer combination was No.3 in Table 5 as the pipes which were mixed with 2000 ppm of PH1, 2000 ppm of PH2, 1000 ppm of high-molecular HA1, 2000 ppm of PH5 and 5000 ppm of low-molecular HA3.

The crosslink degrees of No.2 and No.3 were $86 \%$ and $87.8 \%$, respectively. The oxidative induction time of No.2 was approximately twice the time than that of No.3 [16].

\subsection{Hydrostatic Pressure Test}

Table 6 shows the results of hydrostatic pressure tests. It was found that the pipes subjected to the low hoop stress 
Table 4. Physical properties of stabilizers for peroxide cross-linking polyethylene pipes.

\begin{tabular}{|c|c|c|c|c|c|c|c|c|c|c|}
\hline \multirow{2}{*}{$\begin{array}{l}\text { System } \\
\text { Abbrev. }\end{array}$} & \multicolumn{7}{|c|}{ Phenol system antioxidants } & \multicolumn{3}{|c|}{ Hindered amine light stabilizers } \\
\hline & PH1 & PH2 & PH3 & PH4 & PH5 & PH6 & PH7 & HA1 & HA2 & HA3 \\
\hline $\mathrm{T}_{\mathrm{m}}\left({ }^{\circ} \mathrm{C}\right)$ & 120 & 53 & 63 & 240 & 225 & 14.2 & 125 & 150 & 150 & 140 \\
\hline Molecular weight (-) & 1178 & 530 & 642 & 775 & 553 & 424 & 741 & 2286 & 3400 & 722 \\
\hline Max concentration (ppm) & 5000 & 5000 & 2000 & 5000 & 2000 & - & 3000 & 1000 & 3000 & 5000 \\
\hline
\end{tabular}

Table 5. Stabilizer combination for peroxide cross-kinked polyethylene pipes.

\begin{tabular}{|c|c|c|c|c|c|c|c|c|}
\hline \multirow{2}{*}{ Combination No. } & \multicolumn{2}{|c|}{ Phenol system (ppm) } & \multicolumn{3}{|c|}{ Hindered amine light stabilizers (ppm) } & \multirow{2}{*}{$\frac{\text { Metal deactivator }(\mathrm{ppm})}{\text { HA5 }}$} & \multirow{2}{*}{$\begin{array}{l}\text { OIT } \\
\text { (min) }\end{array}$} & \multirow{2}{*}{$\begin{array}{c}\text { Crosslink } \\
\text { degree (\%) }\end{array}$} \\
\hline & PH1 & PH2 & HA1 & HA2 & HA3 & & & \\
\hline 1 & - & 2000 & - & - & - & - & 2.8 & 93.5 \\
\hline 2 & 2000 & 2000 & 1000 & 3000 & 0 & 2000 & 421.8 & 86.0 \\
\hline 3 & 2000 & 2000 & 1000 & 0 & 5000 & 2000 & 217.8 & 87.8 \\
\hline
\end{tabular}

Table 6. Results of hydrostatic pressure tests.

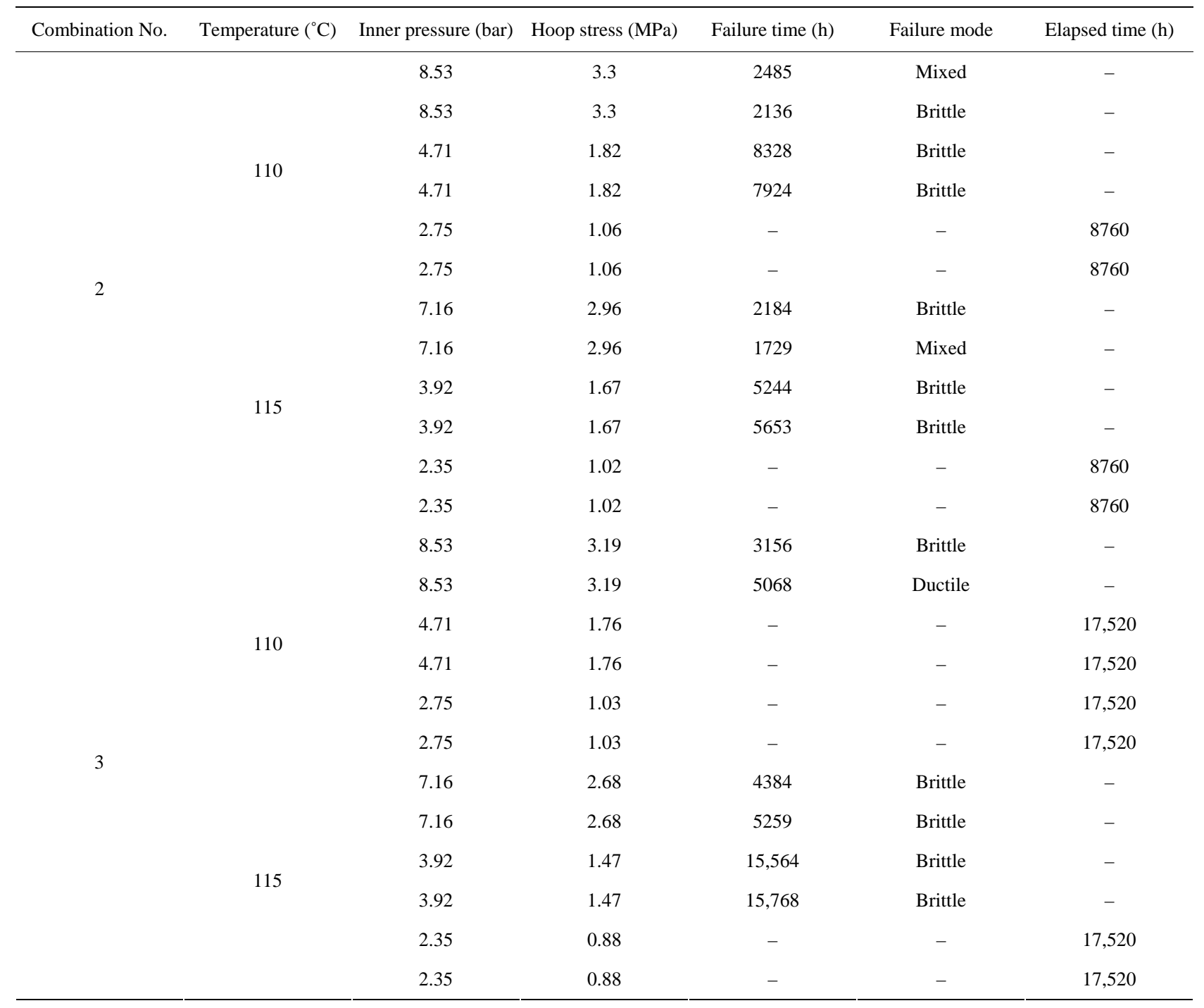




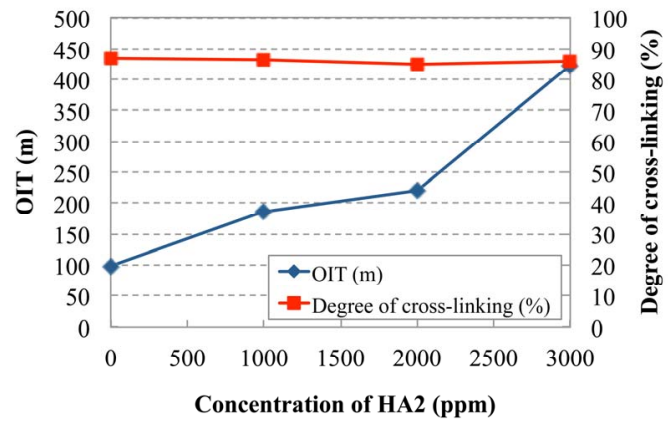

Figure 2. Change of crosslink degree and oxidative induction time by concentration of HA2 with PH2(2000), PH1 (2000), PH5(2000), and HA1(1000).

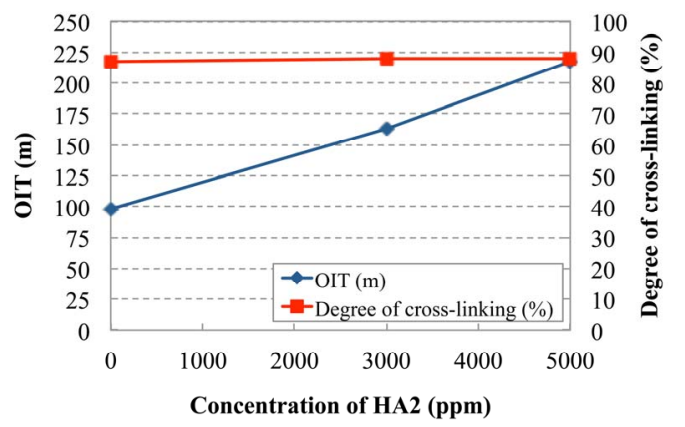

Figure 3. Change of crosslink degree and oxidative induction time by concentration of HA3 with PH2(2000), PH1 (2000), PH5(2000), and HA1(1000).

(about 1MPa) for No.2 and No.3 were durable over 8760 hours at $110^{\circ} \mathrm{C}$. However, the pipe subjected to the high hoop stress (about 1.8 MPa) for No.2 was failed in brittle mode under 8760 hours. On the other hand, the pipe subjected to the high hoop stress (about 1.8 MPa) for No.3 was durable over 7860 hours.

It was also found that the pipes subjected to the low hoop stress (about 1MPa) for No.2 and No.3 were durable over 8760 hours at $115^{\circ} \mathrm{C}$. However, the pipe subjected to the high hoop stress (about 1.5 MPa) for No.2 was failed in brittle mode under 8760 hours. On the other hand, the pipe subjected to the high hoop stress (about $1.5 \mathrm{MPa}$ ) was durable over 15000 hours.

The pipes subjected the low hoop stress of $1 \mathrm{MPa}$ for No. 2 and No. 3 were durable over 8760 hours at 110 and $115^{\circ} \mathrm{C}$. However, the pipe subjected the high hoop stress over 1.5 MPa for No.3 was more durable over 8760 hours at 110 and $115^{\circ} \mathrm{C}$ than No.2. As a result of the hydrostatic pressure test, it was shown to the importance to take account of not only the stress and temperature dependency but also the structure of cross-linking.

\subsection{Hydrodynamic Pressure Tests with the Chlorine Aqueous Solution}

Table 7 shows the results of hydrodynamic pressure tests with the aqueous chlorine solution. It was found that the pipe subjected the high hoop stress of $0.8 \mathrm{MPa}$ for No.3 was more durable over 14,000 hours at $95^{\circ} \mathrm{C}$ than that of No.2.

As a result of the hydrodynamic pressure test with the aqueous chlorine solution, it was shown to the importance to take account of not only the differences of stabilizer combinations but also the structure of crosslinking.

\subsection{Molecular Weight between Cross-Linked Points}

To examine the molecular weight between cross-linked points, the storage elastic modulus was measured in the melting state at $200^{\circ} \mathrm{C}$ by dynamic viscoelastic measurement. The molecular weight between cross-linked points was determined by the following equation.

$$
M e=\frac{\rho R T}{E}
$$

where,

$\mathrm{Me}$ : Molecular weight between cross-linked points

$\rho$ : Density

$R$ : Universal gas constant

$E$ : Storage elastic modulus

Figure 4 shows the relation between the crosslink degree and the molecular weight between cross-linked points of stabilizer combination No.1, No.2 and No.3. It was found that the molecular weight between crosslinked points of No.3 was higher than that of No.2. Because of this, it was appeared that No.3 had a low number of cross-linked points than No.2.

\subsection{Structure of Cross-Linked Region}

The nuclear magnetic relaxation time with NMR can provide the signal of multicomponent reflecting the differences of molecule mobility. In case of polyethylene resin, the nuclear magnetic relaxation time of crosslinked region became shorter extremely with suppression of molecular mobility depending on cross-linked and the nuclear magnetic relaxation time of melting region became longer. And also the nuclear magnetic relaxation time was thought to represent the crosslink density [14].

Table 7. Results of hydrodynamic pressure tests with the chlorine aqueous solution.

\begin{tabular}{ccccc}
\hline $\begin{array}{c}\text { Combination } \\
\text { No. }\end{array}$ & $\begin{array}{c}\text { Temperature } \\
\left({ }^{\circ} \mathrm{C}\right)\end{array}$ & $\begin{array}{c}\text { Inner } \\
\text { pressure } \\
(\text { bar })\end{array}$ & $\begin{array}{c}\text { Elapsed } \\
\text { time }(\mathrm{h})\end{array}$ & Remark \\
\hline 2 & 95 & 3 & 8439 & $\begin{array}{r}\text { Failure at 7897 h, } \\
8120 \mathrm{~h}, 8439 \mathrm{~h}\end{array}$ \\
3 & 95 & 3 & 14,488 & No failure \\
\hline
\end{tabular}


The Carr-Purcell-Meiboom-Gill at 90 pulses was used for measurement with NMR at $200^{\circ} \mathrm{C}$. Figure 5 shows the relation between the crosslink degree and the relaxation time of cross-linked region of stabilizer combination No.1, No.2, and No.3. Figure 6 shows the relation between the crosslink degree and the proportion of cross-linked region of stabilizer combination No.1, No.2, and No.3. Figure 7 shows the relation between the crosslink degree and the proportion of non cross-linked region of stabilizer combination No.1, No.2, and No.3.

It was found that the crosslink density of No.3 was smaller than that of No.2, the proportion of cross-linked region of No.3 was larger than that of No.2 and the proportion of non cross-linked region was larger than that of No.2. Because of these, it was appeared that No.3 had small cross-linked region composed of high crosslink density, but No.2 had large cross-linked region composed of low crosslink density.

\section{Conclusions}

In this research, we tried to evaluate the effects on crosslink degree and the oxygen induction time for the PEX-a

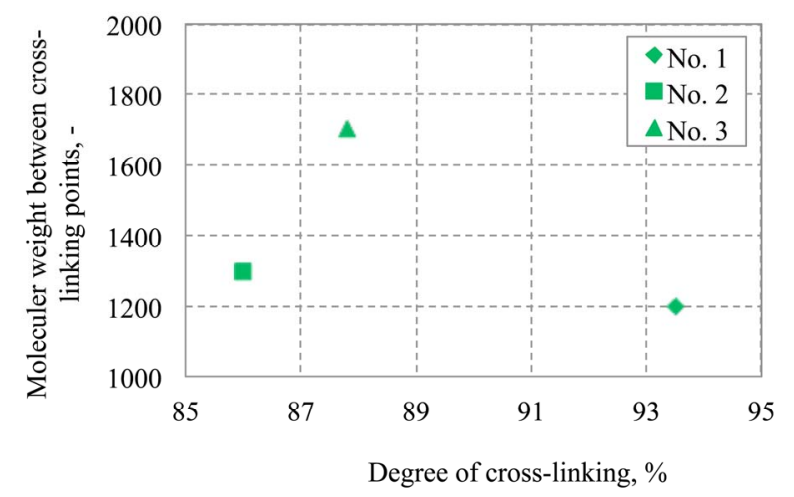

Figure 4. Relation between degree of cross-linking and molecular weight between cross-linked points of stabilizer combination No. 1, No. 2, and No. 3.

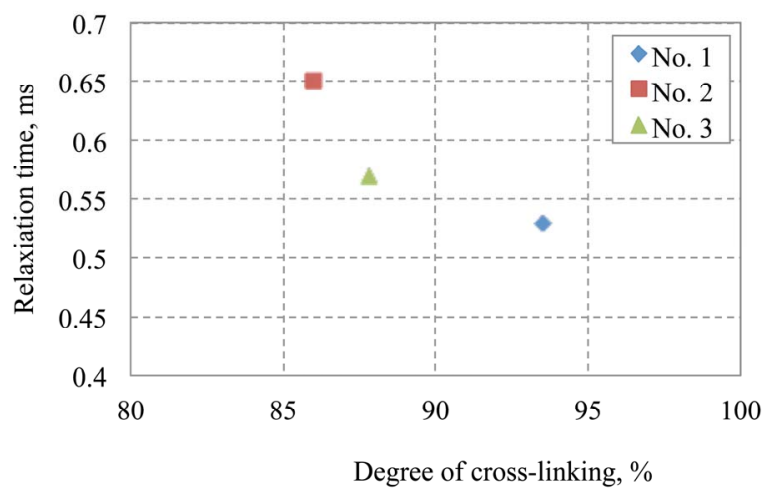

Figure 5. Relation between crosslink degree and relaxation time of cross-linked region of stabilizer combination No.1, No.2, and No.3.

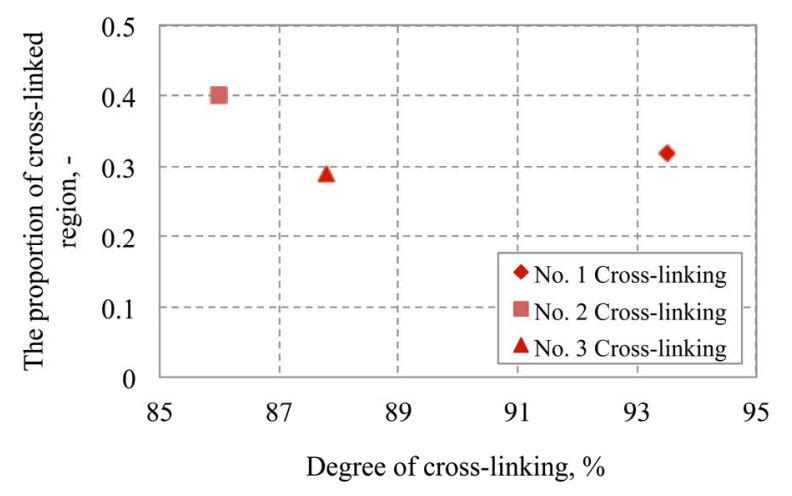

Figure 6. Relation between crosslink degree and the proportion of cross-linked region of stabilizer combination No.1, No.2, and No.3.

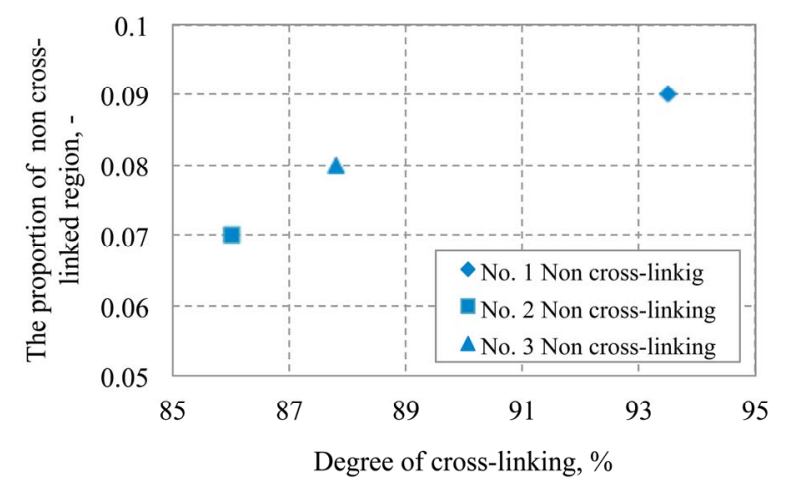

Figure 7. Relation between the crosslink degree and the proportion of non cross-linked region of stabilizer combination No.1, No.2, and No.3.

pipes mixed with several stabilizers. As a result, it was found that the combination of antioxidants for PEX-a pipes plays an important role to prolong the oxygen induction time without inhibiting the cross-linking. As for mixing hindered amine light stabilizer, it was considered that the combination of the high molecular type and low molecular type indicated the better effect for long term durability because of good migration of the low molecular, whereas the combination of two high molecular types was not effective because of poor migration.

From the results of the hydrostatic and hydrodynamic pressure test with chorine, it was found that the failure time of the pipes didn't depend on the oxidative induction time. And it was suggested that not only stress, temperature, or differences of antioxidant combination but also the structure of cross-linking play an important role to the failure time of the pipes.

From the results of the ${ }^{1} \mathrm{H}$ pulsed NMR measurement over the melting point of polyethylene, it was found that each peroxide PEX pipe with different molecular type of hindered amine light stabilizer indicated the different proportion and crosslink density of cross-linked region, 
in addition, that these pipes had the effective structure of cross-linking for the hydrostatic pressure test and the hydrodynamic pressure test with the chlorine aqueous solution. Therefore, it was considered to be useful results for studies of the stricture of cross-linking of polyethylene.

\section{REFERENCES}

[1] C. Munier, E. Gaillard-Devaux, A. Tcharkhtchi and J. Verdu, "Durability of Cross-Linked Polyethylene Pipes under Pressure," Journal of Materials Science, Vol. 37, No. 19, 2002, pp. 4159-4163. doi:10.1023/A:1020091920606

[2] B. Fayolle and J. Verdu, "EWF Method to Study Long Term Fracture Properties of Cross-Linked Polyethylene”, Polymer Engineering \& Science, Vol. 45, No. 3, 2005, pp. 424-431. doi:10.1002/pen.20241

[3] Ghasemi and J. Morshedian, "The Effect of Co-Agent on the Peroxide Crosslinking of LDPE," Iranian Polymer Journal, Vol. 12, No. 2, 2003, pp. 119-125.

[4] J. Barzin, H. Azizi and J. Morshedian, "Preparation of Silane-Grafted and Moisture Crosslinked Low Density Polyethylene. Part II: Electrical, Thermal and Mechanical Properties,” Polymer-Plastics Technology and Engineering, Vol. 46, No. 3, 2007, pp. 305-310. doi:10.1080/03602550601155815

[5] J. Morshedian and P. M. Hoseinpour, "Polyethylene CrossLinking by Two-Step Silane Method: A Review,” Iranian Polymer Journal, Vol. 18, No. 2, 2009, pp. 103-128.

[6] R. Ayyer, A. Hiltner and E. Baer, “A Fatigue-to-Creep Correlation in Air for Application to Environmental Stress Cracking of Polyethylene,” Journal of Materials Science, Vol. 42, No. 16, 2007, pp. 7004-7015. doi:10.1007/s10853-006-1108-2

[7] M. Parsons, E. V. Stepanov, A. Hiltner and E. Baer, "Correlation of Fatigue and Creep Slow Crack Growth in a Medium Density Polyethylene Pipe Material,” Journal of Materials Science, Vol. 35, No. 11, 2000, pp. 26592674. doi:10.1023/A:1004789522642
[8] M. Parsons, E. V. Stepanov, A. Hiltner and E. Baer, "Effect of Strain Rate on Stepwise Fatigue and Creep Slow Crack Growth in High Density Polyethylene,” Journal of Materials Science, Vol. 35, No. 8, 2000, pp. 1857-1866. doi:10.1023/A:1004741713514

[9] J. Weon, "Effects of Thermal Ageing on Mechanical and Thermal Behaviors of Linear Low Density Polyethylene Pipe," Polymer Degradation and Stability, Vol. 95, No. 1, 2010, pp. 14-20. doi:10.1016/j.polymdegradstab.2009.10.016

[10] J. Viebke and U. W. Gedde, “Assessment of Lifetime of Hot-Water Polyethylene Pipes Based on Oxidation Induction Time Data," Polymer Engineering \& Science, Vol. 38, No. 8, 1998, pp. 1244-1250. doi:10.1002/pen.10293

[11] X. Colin, L. Audouin, J. Verdu, M. R.Evesque, B. Rabaud, F. Martin and F. Bourgine, “Aging of Polyethylene pipes Transporting Drinking Water Disinfected by Chlorine Dioxide. Part II-Lifetime Prediction,” Polymer Engineering \& Science, Vol. 49, No. 8, 2009, pp. 1642-1652. doi:10.1002/pen.21387

[12] Basell Polyolefins, “Technical Manual-Materials Used in Pipe Extrusion,” 2005.

[13] A. Whelton, A. Dietrich and D. Gallagher, "Contaminant Diffusion, Solubility, and Material Property Differences between HDPE and PEX Potable Water Pipes,” Journal of Environmental Engineering, Vol. 136, No. 2, 2010, pp. 227-237. doi:10.1061/(ASCE)EE.1943-7870.0000147

[14] T. Nishi, "Physical Chemistry of Crosslinking," Journal of The Society of Rubber Industry, Japan, Vol. 75, No. 2, 2002, pp. 48-54. doi:10.2324/gomu.75.48

[15] H. Iwabuki, K. Nagaya, T. Noguchi and E. Yamada, "Studies on Structures and Dynamic Properties of Peroxide-Crosslinked EPDM, Part 1. Network Structures in Peroxide-Crosslinked EPDM Examined by Dynamic Mechanical Analysis and Pulsed NMR," Journal of The Society of Rubber Industry, Japan, Vol. 75, No. 9, 2002, pp. 409-414. doi:10.2324/gomu.75.409

[16] D. E. Duvall and D. B. Edwards, "Field Failure Mechanisms in HDPE Potable Water Pipe,” SPE-ANTEC Technical Papers, No. 57, 2011, pp. 1436-1441. 